\title{
Exploiting Web-Based Technology to Foster IPDT Productivity
}

\author{
Phillip J. Brown \\ Systems Engineering Associates, Inc. \\ P.O. Box 763220 \\ Dallas, TX 75376-3220 \\ phil.brown@seConcepts.com
}

\author{
Jack K. Lavender, Jr. \\ Lockheed Martin Vought Systems \\ PO Box 650003-0003 M/S L14-01 \\ Dallas, TX 75265-0003 \\ jack.lavender@1mco.com
}

\begin{abstract}
Very few organizations are able to show a "bottom line" impact directly attributable to investments in information technology. While many reasons are postulated for this failure to produce measurable improvements, a large part of the solution appears to be getting the user involved in defining requirements, identifying cost benefits, and implementing reengineered product development processes.

This approach was tried and validated for the Integrated Product Development Team (IPDT) on which it was applied. The product was a ground based weapon system. Results of the experiment exceeded expectations. Utilization of the system engineering process was an essential element in making this a successful endeavor.

Described herein is the process by which IPDT perspectives were changed, the role of cost benefit analysis, results obtained, and what was learned about transforming a well-established culture.
\end{abstract}

\section{INTRODUCTION}

Information Technology (IT) is at the heart of an ongoing revolution transforming the business landscape. While some companies are making substantial business model changes, far too many companies still relegate IT to automating existing processes. Transforming traditional processes to reduce the labor content of product development costs is a formidable task. Consequently, “...organizations appear to be very slow in exploiting and utilizing technology to increase the effectiveness of knowledge production." (Morton, 1991). The result is a continuing failure to truly exploit IT advances to produce significant productivity improvements.

On the other side of the ledger, the maturation of computer technology, in combination with changing corporate structures, is forcing a new paradigm on information systems managers (Fried, 1995). According to Fried, "the 'controls' over the use of computers by centralized information systems management will erode to a few critical aspects." Application ownership and responsibility for information systems planning and control will gravitate to business process managers. One can also expect to see more outsourcing and corporate or business unit data centers having to compete for business. Most importantly, from the perspective of the experiment described in this paper, an organization's in situ information system is becoming viewed as a utility in the same way the telephone is a utility.

This progression of advances in the use of IT can be observed in several of the technical papers presented at recent INCOSE symposiums. The seed for the project described herein was planted by a demonstration at the 1996 Boston symposium. The automated system demonstrated managed the specification management process for the F/A-18E/F Super Hornet (Kepchar, 1996). The installed system used both the project's Intranet and the external Internet to link the customer and other organizations to the requirements database. A second paper presented in Los Angeles (Scheurer and Kepchar, 1997) provided more information on accomplishments. Further evidence of how innovative use of IT can enhance IPDT productivity was presented at an INCOSE sponsored technical tour of the Jet Propulsion Laboratory (JPL). JPL's concept design center is described in a paper presented at the Vancouver symposium (Aguilar, Dawdy, and Law, 1998).

\section{ENABLING TECHNOLOGIES}

Recent advances in client/server technology are creating new opportunities for innovative process improvements. Key enabling technology was provided in the summer of 1991 by Tim Berners-Lee (Brody, 1996) with the establishment of open communication standards freeing document exchange from platform dependence. Berners-Lee conceived his work as making the Web usable ".... as a communications tool that would enable small groups to work more efficiently in teams." Organizations were suddenly free to assemble computer hardware infrastructures tailored to individual requirements. The need to purchase expensive, propriety software to facilitate information transfer across functional domain boundaries virtually disappeared. 
The introduction, in December 1994, of a low cost browser by Netscape, and subsequent proliferation of this and other browsers throughout the business world, has created a new communication milieu. Within two years, a majority of companies in government counterpart, approved the phased concept implementation plan outlined in Figure 1. He reserved the right to cancel the implementation if the promised utility failed to materialize. In addition to starting simply and adding functionality based on user

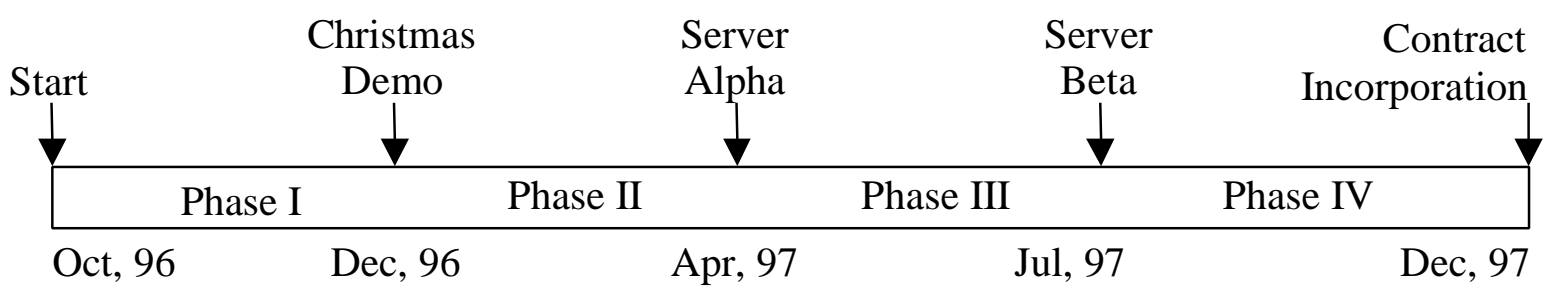

Figure 1 Web Based Collaboration System Institutionalized in Follow-on Contract

the United States had installed browsers for their employees. Books were being written (Benett, 1996 and Bernard, 1996) and the concept of an Intranet entered the IT lexicon.

With the appearance of personal computers on every desk, browsers on every computer, and the connectivity provided by TCP/IP networks, the concept of the corporate information processing utility had become real.

Other important enabling technology came in the form of a new database oriented scripting package named Cold Fusion ${ }^{\mathrm{TM}}$ by the Allaire Corp. This software provided the means for a server to access company maintained Oracle databases containing manufacturing, quality and financial data. The connectivity provided by Cold Fusion ${ }^{\mathrm{TM}}$ meant a project or program dedicated server could function as the focal point for all information needs.

Finally, the heavy dependence on drawings as a product development communication vehicle meant a means must be devised to make them viewable from all computers on the net. The apparent solution was purchasing expensive, proprietary software. Then it was discovered Adobe PDF files could be generated from all the Computer Aided Drawing (CAD) packages being used by hardware designers. This solution was "good enough" for team needs. The viewer was free and it ran on all of our computer platforms.

\section{CONCEPT IMPLEMENTATION ENVIRONMENT}

Engineering and other discipline managers are rightfully reluctant to accept the risk of altering timeproven development processes without compelling reasons to change. In the process transformation described herein, management was told to either substantially reduce product development costs or face program termination by the Department of Defense.

Knowing the threat of cancellation was real, the director of the Line-of-Sight Anti-Tank (LOSAT) weapon system program, in concert with his needs, it was incumbent on system developers to demonstrate to product development team members how this new way of working made each of their jobs easier.

\section{SYSTEMS ENGINEERING PROCESS IMPLEMENTATION}

Transforming IPDT processes was accomplished over a 15-month period, as illustrated in Figure 1. There were four distinct cycles which contained the classic system engineering elements (Sage, 1995). Each cycle contained a requirements and specification activity, logical design and architecting, detailed design and testing, operational implementation, evaluation and modification. Each cycle added functionality based on perceived cost benefits and project management needs.

The first cycle consisted of defining, prototyping, demonstrating and evaluating a very simple webbased project Intranet. Phase II entailed collecting user requirements, specifying a program specific architecture, setting initial implementation priorities and goals, producing an alpha system, and encouraging user feedback on system utility. The next two cycles featured increasingly active user feedback, modification of systems requirements, expanding net links to customers and subcontractors, user testing of implemented features, and data collection to refine early cost-benefit estimates.

Previous experience with document vaulting suggested we had ignored internal customers and created a bottleneck with a single gatekeeper. The solution was to create a web-based self-service document vault. The document vault database would primarily consist of document pointers and summary information, also known as meta-data. The concept was to replace file cabinets with the document vault.

It is interesting to note that most members of the IPDT were unaware that systems engineering principles were being applied in defining, developing and deploying our web-based collaboration tool. One individual, when informed of this late in the development process, noted it was a good thing the 


\begin{tabular}{|l|c|c|c|c|c|c|c|c|c|c|}
\hline \multirow{2}{*}{ Product } & \multicolumn{3}{|c|}{ Engineering } & \multicolumn{3}{c|}{ Operations } & \multicolumn{3}{c|}{ Project } & \multirow{2}{*}{ Location } \\
\cline { 2 - 12 } & System & Mech & Elec & Mfg & Materials & Quality & Finance & Mgmt & Contracts & \\
\hline Specifications & $\mathrm{C}$ & $\mathrm{C}$ & $\mathrm{C}$ & $\mathrm{U}$ & $\mathrm{U}$ & & $\mathrm{U}$ & $\mathrm{U}$ & $\mathrm{U}$ & Digitial/FC \\
\hline Design Documents & $\mathrm{C}$ & $\mathrm{C}$ & $\mathrm{C}$ & $\mathrm{U}$ & $\mathrm{U}$ & $\mathrm{U}$ & & $\mathrm{U}$ & & Digitial/FC \\
\hline ECAD & $\mathrm{U}$ & $\mathrm{U}$ & $\mathrm{C}$ & $\mathrm{U}$ & $\mathrm{U}$ & $\mathrm{U}$ & & & & Digitial/FC \\
\hline MCAD & $\mathrm{U}$ & $\mathrm{C}$ & $\mathrm{U}$ & $\mathrm{U}$ & $\mathrm{U}$ & $\mathrm{U}$ & & & & Digitial/FC \\
\hline BOM & & $\mathrm{U}$ & $\mathrm{U}$ & $\mathrm{U}$ & $\mathrm{U}$ & $\mathrm{U}$ & & & & Digitial/FC \\
\hline Work Instructions & & $\mathrm{C}$ & $\mathrm{C}$ & $\mathrm{U}$ & $\mathrm{U}$ & $\mathrm{U}$ & & & $\mathrm{U}$ & Digitial/FC \\
\hline Letters & $\mathrm{C}$ & $\mathrm{C}$ & $\mathrm{C}$ & $\mathrm{C}$ & $\mathrm{C}$ & $\mathrm{C}$ & $\mathrm{C}$ & $\mathrm{C}$ & $\mathrm{C}$ & Digitial/FC \\
\hline Reports & $\mathrm{C}$ & $\mathrm{C}$ & $\mathrm{C}$ & $\mathrm{C}$ & $\mathrm{C}$ & $\mathrm{C}$ & $\mathrm{C}$ & $\mathrm{C}$ & $\mathrm{C}$ & Digitial/FC \\
\hline Directives & $\mathrm{U}$ & $\mathrm{U}$ & $\mathrm{U}$ & $\mathrm{U}$ & $\mathrm{U}$ & & $\mathrm{U}$ & $\mathrm{C}$ & $\mathrm{C}$ & Digitial/FC \\
\hline Schedules & $\mathrm{C}$ & $\mathrm{C}$ & $\mathrm{C}$ & $\mathrm{C}$ & $\mathrm{C}$ & $\mathrm{C}$ & $\mathrm{C}$ & $\mathrm{C}$ & $\mathrm{C}$ & Digitial/FC \\
\hline Planning & & & & $\mathrm{C}$ & & $\mathrm{C}$ & & & & Digitial/FC \\
\hline
\end{tabular}

Legend: C - Create U - Use FC - Filing Cabinent ECAD - Electronic CAD MCAD - Mechanical CAD BOM - Bill of Materials

Figure 2 Mapping Products to Users Defined Architectural Requirements

use of the system engineering process was not well known because it would have worked against getting team members involved and working together to make the system work.

\section{REQUIREMENTS ELICITATION}

Team interest in implementing an IPDT centered Intranet grew with each system demonstration. Early in Phase II, this interest manifested itself in the spontaneous formation of an ad hoc group looking at how Intranet technology could improve program processes. The group met bi-weekly. A manager from the Quality Organization facilitated discussions.

The authors, as group members, were most interested in identifying all information transactions normally used to develop, test and deploy a weapon system. To elicit this information, the following questions were repeatedly asked. What products do we create to communicate the design to team members? Who creates and/or uses this information? When is information exchanged between team members? Where is the information created, stored and used? How do the members gain access to the information?

Figure 2 illustrates the format of the resulting requirement matrix. The top of the matrix shows the organization from which users originated. Down the left-most column is a list of information products. Information storage locations are listed in the rightmost column. Contained within the body of the matrix are identifiers for the creators and users of these products. The actual matrix was 59 information products versus 13 organizations.

Information products were classified into five types.

1. Revision Tracked Document. This is characterized as a stand-alone document. These documents capture the design or apply process controls. We are concerned about controlling access and keeping version history. Examples of these are CAD Drawings, Specifications, and Design Information Releases.

2. Latest version only. For this type of data, we are only interested in the current version of the document. This does not mean that the creator should not keep up with the change history, but that project team members are only interested in the latest version.

3. Simple Databases. Forms usually characterize this type. The clear regular patterns of form data elements usually yield a small database. This data type is usually used to direct resources, so status tracking is required. Good examples of this are Action Items and non-conformance tags. They are serialized, assigned for processing, and their status and disposition is tracked. An example of a popular simple database is a "history" database. This provides the user a way to track events as a function of time.

4. Legacy Open Database. This category did not come about until later. It was the Cold Fusion ability to access ODBC (Open Database Connectivity) databases that made it possible to put web front ends on our ORACLE and MS Access databases. This makes it possible to provide a simple front end for the casual user to pull the data.

5. Too Hard. This category represents the items that were deemed too difficult to work. Reasons for this were both technical and political.

After looking at group informational needs (and in numerous file cabinets), it was evident most of the information produced by and for the IPDT is in the form of documents. Only a small part of data needed for product development is stored in databases. 


\section{SETTING PRIORITIES}

The authors established requirements and objectives for the initial proof of principle cycle. The critical issue was demonstrating to company and customer management that the existing information utility would support a project Intranet. Three months were allocated to prepare for a system demonstration the week before Christmas. The schedule was met and the concept validated with a working demonstration. Sufficient functionality was demonstrated to see the tools potential for enhancing IPDT productivity.

Moving into Phase II, the focus shifted to identifying high-leverage process changes. Because of the multi-disciplined requirement effort described above, process improvement ideas exceeded the resources available for implementation. Some issues, such as mechanical engineers being able to view CAD generated drawings on their computers, were considered show stoppers. All such issues were given top priority. With so many other process improvement opportunities having been identified, it became clear that effort should be applied to collecting cost benefit information.

Results were astonishing. Seven months into the implementation (early May) it was clear that the volume of paper "pushed" at IPDT members had dropped considerably. Based on already realized results, it was estimated that over the five-year life of the weapon system development program, 12,500 pounds of paper would be saved. Additional cost savings were identified for digitizing log books; producing integration and test documents; eliminating individual filing, storing, and retrieving paper copies of program specific information; problem resolution through electron teleconferencing; and reducing the time spent in IPDT meetings due to improved communication through the Intranet (such time reductions had already been observed over the preceding two months).

Initial cost savings for the approximately fiftyperson development teams were estimated to average 1.8 million dollars a year. Implementation cost, primarily labor, was estimated to average $\$ 37,000$ a year. With a majority of cost savings attributable to digitizing the log books used by quality to track hardware and software system elements, it was clear that "log books" should be the top development priority.

\section{IPDT BUY-IN}

With project management approval to proceed into phase II, attention turned to convincing IPDT members that a web-based information system could improve every person's productivity. The ad hoc requirements definition group helped by making those people part of the solution. To build credibility with other users, as well as members of the requirements group, new web functionality was incrementally added, tested and improved based on user feedback. Three months were allotted for implementing an alpha collaboration tool.

The web architecture mirrored the functions performed by the different organizations and was organized so that each group could add whatever they thought appropriate. For example, the Electronic Systems Department had their own web page, which they maintained and used to post design information. To accelerate adding content to the web, a class on web-page basics was developed and taught several times to build a cadre of Hypertext Markup (HTML) authors. (This in-house class became the most popular in the division.) Everyone was urged to use the web for communicating with colleagues.

The younger members of the team immediately accepted the web and started adding functionality to make their job easier. Those managers that were computer literate also made a quick transition. The problem was bringing on-board those individuals with little or no computer experience. This became evident at a meeting held in late March of all the lead managers for the program. After a presentation reviewing what had been accomplished and what remained to be done, each person in the room was asked if they could wholeheartedly support relying on the web for their information needs. A surprising amount of angst still existed.

An additional three months was allocated to implement a beta web-based information system. Problems solved included transitioning from static file based information retrieval to dynamic information retrieval, improving the document vaulting feature, and migrating to a company maintained server. With increasing use came a higher frequency of user problems. Solving these problems was always accorded the highest priority. The return was a growing number of adherents for our webbased tool. 


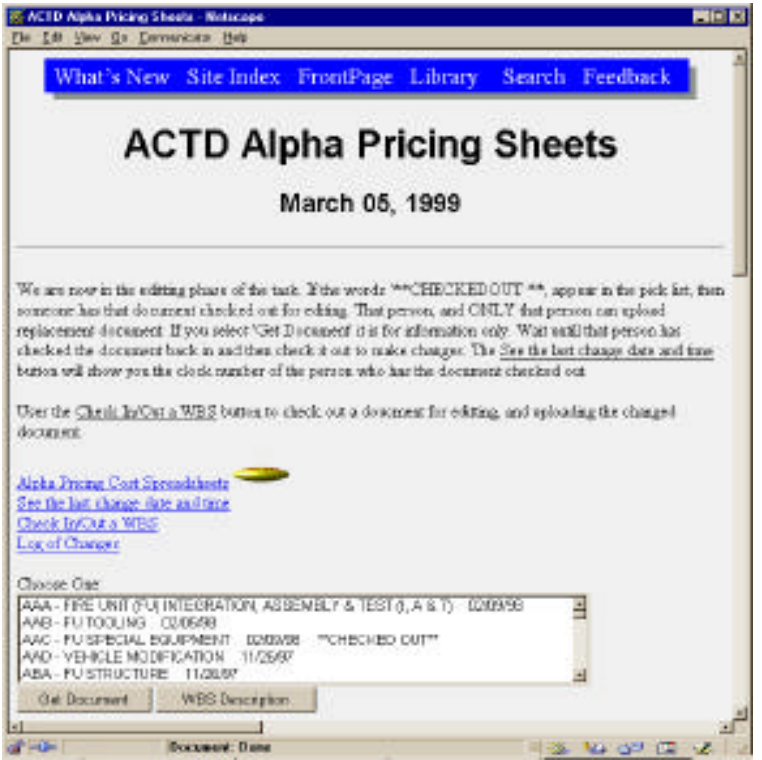

Figure 3 Product and Task Descriptions

The event that converted the remaining doubters was the preparation of a major proposal for the customer. System maturity was such that the program director mandated all product and task descriptions be posted on the web broken out by Work Breakdown Structure (WBS) element. For the first time, all disciplines and domains could keep up with what others were writing almost as quickly as it was being written. And the project director could continually monitor the progress of the preparation process and whether write-ups were consistent with the scope of work. A document checkout system, illustrated in Figure 3, allowed revisions as needed and provided a record of when documents were last updated. By the time the due date for product descriptions was reached, almost every problem and discontinuity had been resolved.

Based on the task descriptions prepared for each Work Breakdown Structure (WBS) element, work was spread to time on pricing sheets. The Finance department specified the format to use. With the help of the automation and communication provided by the web, departments were sometimes able to resolve budget allocation conflicts without the help of project management. Surprises were reduced and management was again able to monitor the cost estimate build-up by department.

Upon proposal submittal, all parties agreed that this new way of working was a vast improvement over what had been done in the past. Web based collaboration proved itself to be a better way to work.

Our guiding implementation philosophy was always "keep it simple" and to use the available tools. The heart of the system was the product document vault. Having a central repository for all product design information allows users to view data in many different dimensions.

\section{ACCOMPLISHMENTS}

By far the biggest implementation challenge was overcoming resistance to change. Increasing user involvement in improving system utility eventually produced the necessary critical mass of proponents. Classical systems engineering activities served to pull users into defining requirements, developing solutions, and continuously improving the existing web-based information system. Building support and overcoming reservations about relying on IT collaboration tools meant always assigning the highest priority to fixing problems reported by team members. In return, we eventually gained IPDT endorsement and acceptance of the value of cultural change

Drawings are an essential ingredient to product development. By using the document vault to create an indentured drawing list, as shown in Figure 4, the IPDT had an organized, relatively easy way to locate drawings, engineering releases, engineering orders, and digital pictures. This feature became very popular and is used as one of the primary portals to the design information.

Many individuals added web enhancements on their own initiative. For example, all program milestone schedules used in bi-weekly status meetings were made viewable with a Netscape browser. Weekly labor charges prepared by the Finance department were placed on the web. After using the web to prepare a cost proposal, everyone agreed it

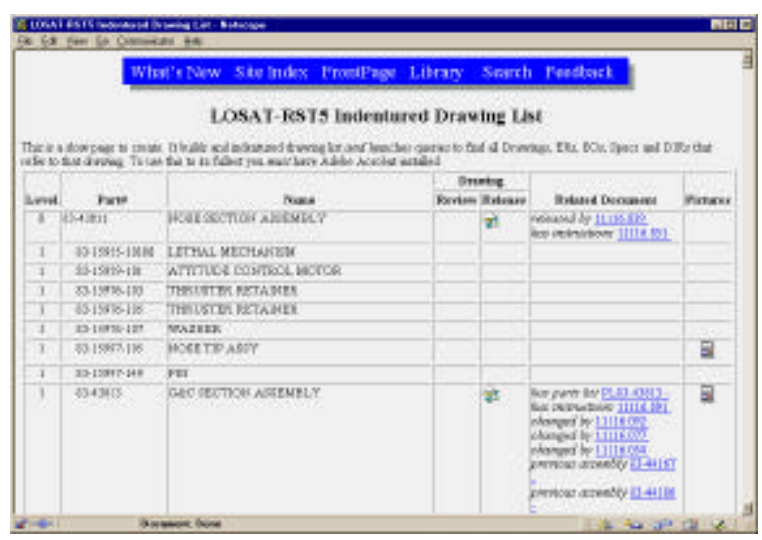

\section{Figure 4 Indentured List Provides Access to Design Documents}

had cut preparation time and improved one's ability to align their work with others since the most recent task descriptions were always available for viewing.

Creating a cadre of people capable of authoring Intranet documents (HTML) also produced unexpected results. Graduates of the web page basics course started creating web pages to post on the division's internal net. Records indicated many of the hits on our system originated from outside the project. Demand for servers and locations for web pages were such that the information technology group requested 
a special class to teach their people HTML. The genie was out of the bottle.

The follow on contract received from the U.S. Government contained language endorsing our web based collaboration system.

\section{COST-BENEFITS}

Upper management was informed in early May 1997 of the exciting cost benefits available for improving IPDT productivity across the division. It was suggested internal funds be reallocated to accelerate capturing the predicted productivity improvements. A review of the proposal by engineering management produced the observation that the numbers did not add up. Moreover, it was said all internal money had already been allocated for the current fiscal year.

With electronic log books having attracted the lion's share of the criticism, a small ad hoc group set about collecting what the company was actually spending on log books. (No one knew.) Upon gathering the program's actual log book costs, and analyzing the labor hour reductions expected from using electronic media, it was determined the previous estimated total cost avoidance benefit of $\$ 8.6$ million was too low. The new analysis indicated a cost avoidance benefit of $\$ 20.2$ million, or more than $\$ 4.0$ million per year. Cost to implement was estimated to be $\$ 299,000$. This works out to a Return On Investment (ROI) of 6,700 percent, i.e. \{[( $\$ 20.2 \mathrm{x}$ $\left.\left.\left.10^{6}\right) /\left(\$ 299 \times 10^{3}\right)\right] \times 100\right\}$. With the company having several programs using the manual log book system, productivity improvements from implementing an electronic log book system across the division would be considerable.

ROIs for other process improvement ideas ranged from a low of 400 percent to several thousand percent. Most were deferred for implementation because the magnitude of the projected cost avoidance did not compare to what could be captured with the log book project.

These eye-catching ROIs result from piggybacking Intranet enabled process improvements on the existing information system utility. For most of the ROIs calculated, the primary cost was simply the labor of a very capable webmaster. Unleashing the creativity of IPDT members produced a number of labor saving improvements never analyzed as to their benefit. It is safe to say the cost avoidance numbers that engineering management rejected in May as overstated was in fact far too low.

\section{LESSONS RELEARNED}

Introducing innovation is difficult in any organization (Utterback, 1994). This is not a new phenomenon. Machiavelli observed in 1532:

"It must be considered that there is nothing more difficult to carry out, nor more doubtful of success, nor more dangerous to handle, than to initiate a new order of things. For the reformer has enemies in all those who profit by the old order, and only lukewarm defenders in all those who would profit by the new order, this lukewarmness arising partly from fear of their adversaries, who have the law in their favor; and partly from the incredulity of mankind, who do not truly believe in anything new until they have had actual experience of it. (Machiavelli, 1952)"

Key to having the time to gain team acceptance of this new way of working was the steadfast support of the program director. Six months into the project, a presentation summarizing accomplishments was given to lead managers on the program. At the conclusion of the presentation, each was asked if he or she thought implementing an Intranet would help save money. Support was mixed. The effort continued with the program directors endorsement of the authors' vision.

Time gradually resolved the "incredulity" factor as people began to work with the system and discover it made their job easier. The cyclic approach of build a little, test, evaluate, and improve meant users were introduced to new functionality in easy to learn steps. Users learned their feedback was an important element in the process of improving functionality. This success story is a testament to the value of the system engineering process. Perhaps Machiavelli would have not have been exiled by the Florentines if he had had a good systems engineer on his staff.

\section{AFTERWORD}

Fifteen months have passed since the completion of this project. Figure 5 displays the current LOSAT Front Page that is the portal into almost all program essential information. We are currently averaging 100 user sessions per day.

Under a division-wide Quality Leadership Council, a team is working to integrate log books into a PDM (Product Data Manager).

Most contract deliverables are being delivered on our collaboration system.

Our internal business reports are being delivered on our system (reducing the copy-center demand).

All the elements of the System Technical Description are contained and distributed within our system.

Product design information is shared with the customer on a real time basis by using "Extranet" technology

Engineering tests are being cataloged and distributed using our system to integrate pictures, movies, and reports.

Most heartening is the way some of our most ardent IPDT critics have become Intranet proponents. 


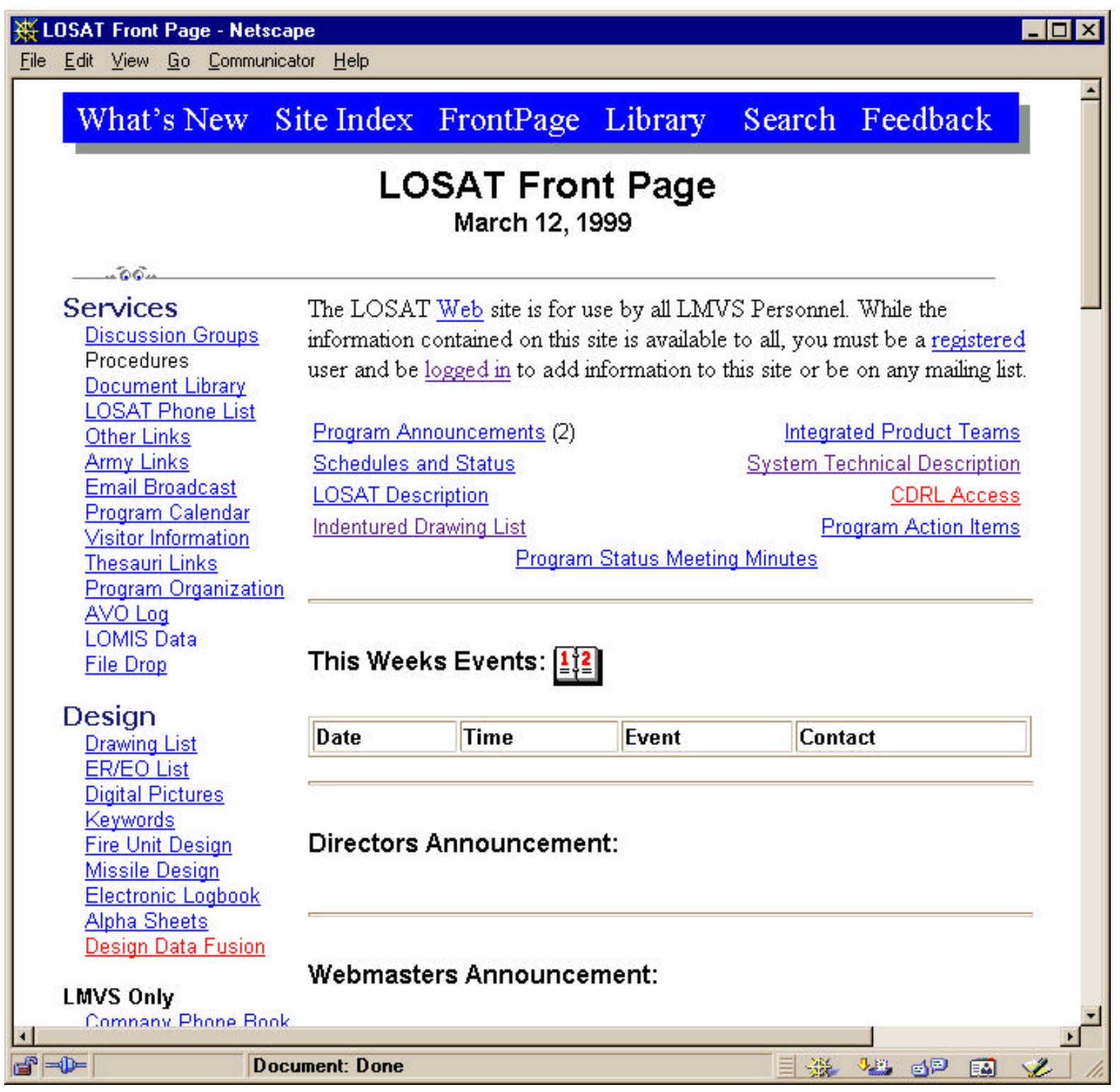

Figure 5 Current Starting Page

The success of this undertaking is a testament to the creativity and adaptability of all the IPDT team members. It was a pleasure to have worked with such a fine group of people.

\section{REFERENCES}

Aguilar, Joseph A., Dawdy, Andrew B., and Law, Glenn W., “The Aerospace Corporation's Concept Design Center," INCOSE Proceedings, 1998.

Benett, Gordon, Introducing INTRANETS, A Decisionmaker's Guide to Launching An Intranet, Que Corporation, Indianapolis. Indiana, 1996.

Bernard, Ryan, The Corporate Intranet: Create and Manage an Internal Web for Your Organization, John Wiley \& Sons, Inc., 1996.
Brody, Herb, "The Web Maestro: An Interview with Tim Berners-Lee," Technology Review, Vol. 99, No. 5, July, 1996.

Fried, Louis, Managing Information Technology in Turbulent Times, John Wiley \& Sons, Inc., New York,. N.Y., 1995.

Kepchar, Kenneth J., "Automating the Spec Management Process," INCOSE Proceedings, 1996.

Machiavelli, The Prince, Luiggi Ricci translation, Mentor Books, New York, N.Y., 1952

Morton, Michael S. Scott, The Corporation of the 1990s, Information Technology and the Organizational Transformation, Oxford University Press, New York, N.Y., 1991.

Sage, Andrew P., Systems Management for Information Technology and Software Engineering, John Wiley \& Sons, New York, N.Y., 1995. 
Scheurer, Robert P., and Kepchar, Kenneth J., "Balancing Requirements and the Product: A Process and Tools Case Study," INCOSE Proceedings, 1997.

Utterback, James M., Mastering the Dynamics of Innovation, Harvard Business School Press, Boston, Massachusetts, 1994.

\section{Biographies}

Phillip J. Brown is a Director of Systems Engineering Associates, Inc. His undergraduate work in engineering was done at Georgia Tech. He has a Master of Science in Industrial and Systems Engineering from Ohio State University. His 32 years of system engineering experience includes work on aircraft, missile systems, rocket systems, satellite systems, and business systems. $\mathrm{He}$ is a licensed professional engineer and a member of the National Society of Professional Engineers. INCOSE service includes three years on the metrics committee and four years on the education and research committee where he is currently co-chair. (http://www.seConcepts.com)

Jack K. Lavender is a System Engineer at Lockheed Martin Vought Sytems currently assigned to the LOSAT (Line-of-Sight Anti-Tank) program as web developer. He has both a Bachelor and Masters Degree in Mathematics from the University of Texas at Arlington. He has over 17 years of systems engineering and information technology experience in designing and developing advanced defense systems and business systems. He has taught numerous programming and HTML courses for the Dallas County Community College. 